Table 1. Baseline characteristics of the patients with DM and PM

\begin{tabular}{|c|c|c|c|}
\hline & $\mathrm{DM}(\mathrm{n}=38)$ & PM $(n=43)$ & $P$ \\
\hline Female, $\mathrm{n}(\%)$ & $27(71.1)$ & $29(67.4)$ & 0.457 \\
\hline Age at onset, years & $33(15-48)$ & $47(38-58)$ & 0.002 \\
\hline \multicolumn{4}{|l|}{ Skeletal muscle features } \\
\hline Muscle weakness, n (\%) & $34(89.5)$ & $37(86.0)$ & 0.451 \\
\hline Myalgia, n (\%) & $23(60.5)$ & $30(69.8)$ & 0.261 \\
\hline Artritis, n (\%) & $8(21.1)$ & 9 (20.9) & 0.601 \\
\hline \multicolumn{4}{|l|}{ Skin features, $\mathrm{n}(\%)$} \\
\hline Heliotrope rash, $\mathrm{n}(\%)$ & $18(47.4)$ & $0(0)$ & $<0.001$ \\
\hline Gottron papules, n (\%) & $25(65.8)$ & $0(0)$ & $<0.001$ \\
\hline Gottron sign, $\mathrm{n}(\%)$ & $18(47.4)$ & $0(0)$ & $<0.001$ \\
\hline Generalize erythema, $\mathbf{n}(\%)$ & $10(26.3)$ & $0(0)$ & $<0.001$ \\
\hline Calcinosis, n (\%) & $4(10.5)$ & $1(2.3)$ & 0.143 \\
\hline Dysphagia, $n(\%)$ & $10(26.3)$ & $12(27.9)$ & 0.537 \\
\hline Interstitial lung disease (ILD), $\mathbf{n}(\%)$ & $8(21.1)$ & $20(47.6)$ & 0.012 \\
\hline Other connective tissue diseases overlap, $\mathbf{n}(\%)$ & $6(15.8)$ & $13(30.2)$ & 0.102 \\
\hline Malignancies, $\mathrm{n}(\%)$ & $5(13.5)$ & $3(7)$ & 0.275 \\
\hline \multicolumn{4}{|l|}{ Laboratory data } \\
\hline Creatine kinase (IU/L) & $505(110-3616)$ & $801(402-1868)$ & 0.655 \\
\hline C-reactive protein $(\mathrm{mg} / \mathrm{dl})$ & $0.3(0.1-0.8)$ & $1.2(0.5-2.8)$ & $<0.001$ \\
\hline $\mathrm{ESR}(\mathrm{mm} / \mathrm{h})$ & $19(8-27)$ & $25(17-48)$ & 0.005 \\
\hline MAAs (Ro-52, pm-scl 100, pm-scl75), n (\%) & 11 (28.9) & $24(55.8)$ & 0.013 \\
\hline MSAs, n (\%) & $28(73.7)$ & $25(58.1)$ & 0.108 \\
\hline Anti- TIF1- $\gamma, \mathbf{n}(\%)$ & $9(23.7)$ & $2(4.7)$ & 0.014 \\
\hline Anti-Jo-1, n (\%) & $2(5.3)$ & $12(27.9)$ & 0.007 \\
\hline Anti-PL-7, n (\%) & 0 & $5(11.6)$ & 0.038 \\
\hline
\end{tabular}

Disclosure of Interests: None declared.

DOI: 10.1136/annrheumdis-2021-eular.3349

\section{AB0447 PREVALENCE OF PRIMARY BILIARY CIRRHOSIS IN SYSTEMIC SCLEROSIS AND SJÖGREN'S SYNDROME OVER TIME: A SYSTEMATIC REVIEW}

S. Upadhyaya ${ }^{1}$, D. Starcevic ${ }^{2}$, M. Turk ${ }^{3}$, J. Pope ${ }^{1} .{ }^{1}$ Western University, Rheumatology, London, Canada; ${ }^{2}$ Western University, Schulich School of Medicine \& Dentistry, London, Canada; ${ }^{3}$ Western University, Medicine, London, Canada

Background: Primary biliary cirrhosis $(\mathrm{PBC})$ is a rare slowly progressive autoimmune disease characterized by inflammatory destruction and fibrosis of intrahepatic bile ducts. It is known to coexist together with rheumatological conditions such as Sjögren's syndrome (SS) and systemic sclerosis (SSc). There is a wide range in reported prevalence of disease overlap with these entities; however, the exact prevalence rates remain unclear.

Objectives: The objectives were to determine the prevalence of: 1) PBC in patients with SS and SSc (and the subsets of limited cutaneous SSc (IcSSc) and diffuse cutaneous SSc (dcSSc)), 2) SSc and SS in patients with PBC, and 3) to analyze changes in frequency over time. SSc occurs in $3 / 10,000$ and PBC in $4-40 / 10,000$ but these rare autoimmune diseases are known to coexist together. We speculated that there could be more cases diagnosed due to increasing availability of standardized antibody tests such as ANA, centromere antibodies, ENA and mitochondrial antibodies.

Methods: A systematic review of the literature was performed using Medline, EMBASE, CINAHL, and the Cochrane Library databases up till June 16, 2020. Only full text articles in the English language with at least 40 patients were included. Cohorts, case series, cross-sectional studies, correspondences and registries with reported prevalence rates of both PBC in patients with SS and SSc as well as SSc and SS in patients with PBC were included. Data on frequency of co-existent diseases was studied by year of publication to determine if prevalence changed over time using linear regression. We used the Strengthening the Reporting of Observational Studies in Epidemiology (STROBE) checklist to assess the quality of the studies.

Results: Of 2876 citations identified, 67 were included in the analysis ( $n=33$ for PBC, 15 for SSc, 18 for SS and 1 for SSc/SS). STROBE checklist scores ranged from 7-21. The prevalence of PBC was $5 \%$ in patients with SSc. Within the subsets, the prevalence of PBC in IcSSc was $8 \%$ and in dcSSc was $1 \%$. In patients with SS, the prevalence of PBC was $4 \%$. The prevalence of SSc overall in those with PBC was $5 \%$ and, within the subsets was $6 \%$ in IcSSc and $0 \%$ in dcSSc. The prevalence of SS in PBC was $18 \%$. There was also no significant association between year of publication and prevalence. There was a lack of standardized definitions so misclassification may have occurred.

Conclusion: PBC is increased in SSc but mostly in the lcSSc subset. SS in PBC is common at nearly 1 in 5 . Over the years, there was no change in the prevalence of PBC in SSc indicating stability over time.

Acknowledgements: Meagan Stanley, Western University Librarian.

Disclosure of Interests: None declared.

DOI: 10.1136/annrheumdis-2021-eular.3433

\section{AB0448 \\ SYSTEMIC SCLEROSIS ASSOCIATED PULMONARY ARTERIAL HYPERTENSION: PREDOMINANCE OF PULMONARY FIBROSIS AS A RISK FACTOR FOR MORTALITY IN A SINGLE CENTER COHORT}

S. Amikishiyev ${ }^{1}$, Y. Yalçınkaya ${ }^{1}$, N. Aliyevaa ${ }^{1}$, K. Mammadova ${ }^{2}$, B. Artim-Esen ${ }^{1}$, A. Gül ${ }^{1}$, A. K. Bilge ${ }^{3}$, G. Okumuş ${ }^{2}$, M. Inanc ${ }^{1} .{ }^{1}$ Istanbul Faculty of Medicine, Istanbul University, Division of Rheumatology, İstanbul, Turkey; ${ }^{2}$ Istanbul Faculty of Medicine, Istanbul University, Department of Chest Diseases, Istanbul, Turkey; ${ }^{3}$ stanbul Faculty of Medicine, Istanbul University, Department of Cardiology, İstanbul, Turkey

Background: Pulmonary arterial hypertension (PAH) is a severe vasculopathic complication for systemic sclerosis (SSc) patients. The availability of oral-specific vasodilator therapies has provided better outcomes.

Objectives: We aimed to analyze the characteristics of SSc-PAH patients and factors associated with mortality.

Methods: Medical records of $291 \mathrm{SSc}$ patients fulfilling ACR/EULAR criteria (2013) and followed-up during 2008-2020 years were screened and the patients who diagnosed $\mathrm{PAH}$ evaluated by right heart catheterization (mean $\mathrm{PAB} \geq 20$ $\mathrm{mmHg})(\mathrm{n}=26,8,9 \%)$ were included into this retrospective cross-sectional study Results: The characteristics of $26 \mathrm{SSc}-\mathrm{PAH}(24$ females) patients were summarised in Table 1.

Table 1. Characteristics of SSc patients with PAH

\begin{tabular}{|c|c|}
\hline & $\begin{array}{l}\text { SSc-PAH } \\
(n=26)\end{array}$ \\
\hline \multicolumn{2}{|l|}{ Demographics } \\
\hline Age(yrs) & $53.6 \pm 8.9$ \\
\hline Duration of Raynaud's(yrs) & $16.1 \pm 11.8$ \\
\hline Duration of Non-Raynaud's(yrs) & $9.2 \pm 6.6$ \\
\hline Raynaud's to Diagnosis of $P A H(\mathrm{yrs})$ & $10.8 \pm 6.7$ \\
\hline \multicolumn{2}{|l|}{ Clinical Characteristics (\%) } \\
\hline LcSSc & $9(34.6)$ \\
\hline DcSSc & $18(65.4)$ \\
\hline Digital ulcer & $14(53.8)$ \\
\hline Gastrointestinal & $20(69.0)$ \\
\hline Synovitis & $5(19.2)$ \\
\hline Flex contractures & $7(26.9)$ \\
\hline Tendon friction rubs & $3(11.5)$ \\
\hline Renal crisis & $1(3.8)$ \\
\hline Pulmonary fibrosis & $19(73.1)$ \\
\hline \multicolumn{2}{|l|}{ Auto-antibodies (\%) } \\
\hline ANA & $23(88.5)$ \\
\hline Anti-centromere & $6(23.1)$ \\
\hline Anti-Scl70 & $13(50)$ \\
\hline \multicolumn{2}{|l|}{ Treatment (\%) } \\
\hline \multicolumn{2}{|l|}{ Specific vasodilator } \\
\hline ERA (bosentan/macicentan/ambricentan) & $15(51.7)$ \\
\hline PDE5-i (sildenafil/tadalafil) & $17(58.6)$ \\
\hline Prostacyclin-analog (İloprost/treprostenil/selexipag) & $15(51.7)$ \\
\hline Riociguat & $5(17.2)$ \\
\hline Immunosuppressives & $21(80.8)$ \\
\hline Steroids & $16(61.5)$ \\
\hline
\end{tabular}

Twenty-four $(92,3 \%)$ of the SSc-PAH patients had PAH-related symptoms at the time of diagnosis, $2(7,7 \%)$ were asymptomatic and diagnosed by screening. $\mathrm{RHC}$ and treatment details were stated in Table 2 .

Table 2. Right Heart Catheterization (RHC) ve treatment details of SScPAH patients

\begin{tabular}{lc}
\hline & $\mathbf{n = 2 6}$ \\
\hline Initial RHC & \\
-mean PAB & \\
-PVR & $30,4 \pm 7,9$ (median $28,20-53 \mathrm{mmHg}$ ) \\
-PCWP & $5,1 \pm 2,4$ (median $4,3-9$ woods) \\
Initial treatment & $10,8 \pm 5,5$ (median $10,0-15 \mathrm{mmHg})$ \\
-monotherapy & $5(19,2 \%)$ \\
-combination & $10(38,5 \%)$ \\
-add-on combination & $12(46,2 \%)$ \\
\hline
\end{tabular}

Eleven out of 26 patients $(42,3 \%)$ were deceased after a mean follow up of $43,7 \pm 24,6$ (median 48,1-84) from PAH diagnosis and 15,1 $\pm 9,9$ (median 13, $0,6-34$ ) years after SSc diagnosis. Deceased patients were younger and had younger age at disease onset $(49,1 \pm 8,8$ vs $56,9 \pm 7,7, p=0.032$ and $30,8 \pm 13,0$ vs $42.0 \pm 10,9,0.027)$. All deceased patients had associated pulmonary fibrosis (100 vs $53.3 \%, p=0.01$ ). No significant difference was observed for initial RHC parameters between deceased and survived SSc-PAH patients. Specific monotherapy was found to be more frequent in deceased patients $(45,5$ vs $0 \%, p=0,007)$. 
Conclusion: The prevalence of SSc-PAH was found to be $8.9 \%$ with increased mortality in our cohort. SSc-PAH patients predominantly had diffuse cutaneous involvement with digital vasculopathy, pulmonary fibrosis, and anti-Scl70 positivity. PAH was diagnosed after a median of 10 years of the Raynaud's, mainly in symptomatic patients. Mortality in PAH-SSc patients was associated with early onset of disease, pulmonary fibrosis, and monotherapy. Initial RHC parameters were not found to be related to mortality.

Disclosure of Interests: None declared.

DOI: 10.1136/annrheumdis-2021-eular.3460

\section{AB0449 CLINICAL CHARACTERISTICS AND RISK FACTORS OF SYSTEMIC SCLEROSIS WITH HEMATOLOGIC SYSTEM DAMAGES}

J. Zheng ${ }^{1}$, Z. R. Dong ${ }^{1}$, Y. P. Tang ${ }^{1}$, Y. Q. Huang ${ }^{2}$, Q. B. Zhang ${ }^{2}$, F. Dai ${ }^{1}$, Y. F. Qing ${ }^{1} .{ }^{1}$ Institute of Rheumatology and Immunology, Department of Rheumatology and Immunology, Nanchong, China; ${ }^{2}$ Institute of Rheumatology and Immunology, Department of Geriatrics, affiliated Hospital of North Sichuan Medical College, Nanchong, China

Background: SSc characterized by varying degrees of fibrosis of the skin and internal organs, clinicians pay more attention to skin and viscera conditions, tend to ignore hematologic system damage. Studies have shown that rheumatic disease such as SLE, RA, pSS often accompanied with hematologic system damages, and hematologic system damages is multiple organ involvement and risk factor of poor prognosis ${ }^{[1-2]}$.

Objectives: To investigate the the clinical features, laboratory characteristics and risk factors of Systemic Sclerosis (SSc) patient with hematologic system damages. Methods: The clinical data of 180 patients were collected from January 2010 to April 2020, at the Affiliated Hospital of North Sichuan Medical College. The demographic information, laboratory tests, and clinical symptoms were analyzed retrospectively.

Results: Among 180 SSc patients, 70(38.9\%) cases were complicated with hematologic system damages. $51(72.9 \%)$ cases had anemia, 24 cases $(34.3 \%)$ had leukopenia, 24 cases (34.3\%) had thrombocytopenia, and 22 cases had hematologic system damages associated with more than two cell line involvement. Clinical symptoms: arthritis was significantly higher in the hematologic system damages group than patient without $(P<0.05)$, however, there was no significantly difference in gender, age, disease course, respiratory symptoms, gastrointestinal symptoms, Raynaud's phenomenon, interstitial lung disease and pulmonary hypertension (all $P>0.05)$. Laboratory tests: ESR and hsCRP were increased in the hematologic system damages group, while the albumin decreased (all $\mathrm{P}<0.05$ ). The positive rates of resistance to anti-dsDNA antibody and anti-ribosomal $P$ protein antibody was higher in the hematologic system damages group (all $P<0.05$ ). Prognosis: During follow-up, leukopenia was more likely to recover, while the thrombocytopenia was more difficult to recover. Logistics regression analysis showed that positive of anti-ribosomal $\mathrm{P}$ protein antibody maght be a risk factor for SSc complicated with hematologic system damages $[\mathrm{OR}=3.930(\mathrm{P}<0.05)]$ (Table 1).

Conclusion: SSc complicated with hematologic system damages is common, and patients with hematologic system damages have more serious clinical symptoms, some of whom have difficulty in recovey. Anti-ribosomal P protein antibody may be a risk factor of SSc hematologic system damages.

Table 1. Bivariate logistics regression analysis on risk factors associated with hematologic damages in SSc.

\begin{tabular}{lccccc}
\hline Factor & $B$ & $S E$ & Wald & $O R(95 \% \mathrm{Cl})$ & $P$ value \\
\hline arthritis & 0.654 & 0.347 & 3.543 & $1.922(0.973-3.797)$ & 0.060 \\
ESR & -0.081 & 0.487 & 0.028 & $0.922(0.355-2.393)$ & 0.868 \\
hsCRP & -0.007 & 0.492 & 0.000 & $0.993(0.379-2.607)$ & 0.989 \\
anti-dsDNA & 0.868 & 0.673 & 1.664 & $2.393(0.637-8.916)$ & 0.197 \\
anti-Rib-P & 1.369 & 0.636 & 4.633 & $3.930(1.130-13.666)$ & 0.031 \\
\hline
\end{tabular}

\section{REFERENCES:}

[1] González-Naranjo L A, Betancur O M, Alarcón G S, et al. Features associated with hematologic abnormalities and their impact in patients with systemic lupus erythematosus: Data from a multiethnic Latin American cohort[J]. Seminars in Arthritis and Rheumatism, 2016,45(6):675-683.DOI:10.1016/j. semarthrit.2015.11.003.

[2] Skare T, Damin R, Hofius R. Prevalence of the American College of Rheumatology hematological classification criteria and associations with serological and clinical variables in 460 systemic lupus erythematosus patients[J]. Revista Brasileira de Hematologia e Hemoterapia, 2015,37(2):115-119. DOI:10.1016/j.bjhh.2015.01.006

Disclosure of Interests: None declared.

DOI: 10.1136/annrheumdis-2021-eular.3465

\section{\begin{tabular}{|l|l}
\hline AB0450 PERIPHERAL MACROVASCULAR INVOLVEMENT \\
\hline
\end{tabular} IN SYSTEMIC SCLEROSIS AS COMPARED WITH HEALTHY CONTROLS: A SMALL COHORT STUDY BY COLOR AND SPECTRAL DOPPLER ULTRASONOGRAPHY}

R. D'alessandro ${ }^{1}$, E. Garcia Gonzales ${ }^{1}$, P. Falsetti ${ }^{1}$, C. Baldi ${ }^{1}$, F. Bellisai ${ }^{1}$, E. Selvi ${ }^{1}$, B. Frediani ${ }^{1} .{ }^{1}$ Rheumatology Unit, Policlinico Le Scotte, Department of Medical Sciences, Surgery and Neuroscience, Siena, Italy

Background: Together with autoimmune-inflammation and fibrosis, microvasculopathy is a hallmark of SSc. However, also macrovascular changes may occur including peripheral proliferative vasculopathy. Whether this changes may represent a specific SSc marker with a predictive value remains a matter of debate. $[1,2,3]$

Objectives: To study peripheral macrovascular involvement by color doppler ultrasound (CDUS) with spectral wave analysis (SWA) in a cohort of 40 SSc patients as compared to healthy controls. To further analyze any differences among the SSc population.

Methods: Forty SSc patients and 36 healthy controls were examined by CDUS with SWA of both hands. Macrovascular involvement was assessed by meas uring the resistivity index (RI) of distal ulnar and radial arteries. Examinations were performed with an Esaote MyLab Twice machine equipped with a linear 10-22 $\mathrm{MHz}$ probe. Ultrasound examination was carried out by two independent rheumatologists blinded to clinical conditions of the patients. Statistical analysis was performed by using MaxStat software.

Results: The RI index resulted increased in the SSc cohort as compared with healthy controls (left ulnar RI 0.977 vs 0.715 ; right ulnar RI 0.996 vs 0.699 ; left radial $\mathrm{RI} 0.988$ vs 0.706 ; right radial $\mathrm{RI} 0.999$ vs 0.688 ; $\mathrm{p}<0.001$ ). SSc patients with an increased $\mathrm{RI}$ in one artery were more probable to have an increased $\mathrm{R}$ in the other vessels too $\left(r^{2}=0.35 ; p<0.01\right)$. In addition, 8 out of $40 \mathrm{SSc}$ patients presented left ulnar artery occlusion (UAO) and 7 out of 40 SSc patients presented right UAO, of which 6 presented bilateral UAO. Awaiting to enlarge the cohort for further analysis, descriptive data regarding increased RI at CDUS/ SWA and clinical features, including years from onset of the disease, subtype of SSc, mRSS, history of digital ulcers, interstitial lung disease and PAH are described in Table 1.

Conclusion: Peripheral macrovascular involvement was observed in SSc patients as compared with healthy controls. Further studies will determine whether this feature may have specificity for diagnosis/prognosis in SSc.

REFERENCES:

[1] Lescoat A, Yelnik CM, Coiffier G et al. Ulnar Artery Occlusion and Severity Markers of Vasculopathy in Systemic Sclerosis: A Multicenter Cross-Sectional Study. Arthritis Rheumatol. 2019;71:983-990.

[2] Lescoat A, Coiffier G, Rouil A et al. Vascular Evaluation of the Hand by Powe Doppler Ultrasonography and New Predictive Markers of Ischemic Digital Ulcers in Systemic Sclerosis: Results of a Prospective Pilot Study. Arthritis Care Res (Hoboken). 2017;69:543-551.

[3] Schioppo T, Orenti A, Boracchi P, De Lucia O, Murgo A, Ingegnoli F. Evidence of macro- and micro-angiopathy in scleroderma: An integrated approach combining 22-MHz power Doppler ultrasonography and video-capillaroscopy. Microvasc Res. 2019;122:125-130.

Table 1. Main clinical features of the SSc cohort $(n=40)$ studied by CDUS for macrovascular involvement.

SSc cohort $(n=40)$

Years from onset

range $(35 \mathrm{y}-0 \mathrm{y})$

mean $=10.5 y$

Autoantibodies

ACA $13 / 40$

Anti-Topol $14 / 40$

Other $13 / 40$

mRSS

range $(0-30)$

ILD

mean $=3$

$17 / 40$

$7 / 40$

Early $10 / 40$

Active $11 / 40$

Late $6 / 40$

History of digital ulcers

$16 / 40$

Left ulnar IR

Left radial IR

Right ulnar IR

Right radial IR

0.977

0.988

0.996

0.999

Disclosure of Interests: None declared.

DOI: 10.1136/annrheumdis-2021-eular.3481 